\title{
EQUATION FOR PREDICTING WEIGHT GAIN IN VERY LOW-BIRTH-WEIGHT INFANTS*
}

William H. Meetze, M.D., F.A.A.P.

The publisher regrets an error in publication of the author's equation for predicting weight gain in very lowbirth-weight infants. The correct equation is:

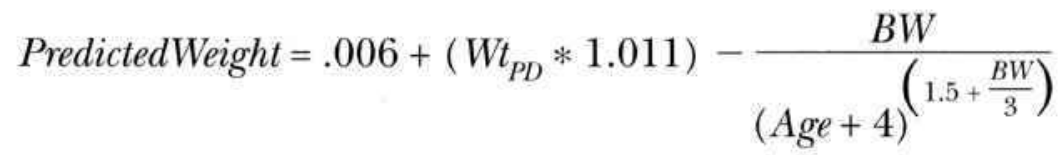

Where $W t_{P D}=$ previous day's weight from the equation $(\mathrm{kg})$,

$B W=$ birth weight $(\mathrm{kg})$, and

Age $=$ age in days $($ birth $=0)$. 